This item was submitted to Loughborough's Research Repository by the author.

Items in Figshare are protected by copyright, with all rights reserved, unless otherwise indicated.

\title{
Improving copper plating adhesion on glass using laser machining techniques and areal surface texture parameters
}

PLEASE CITE THE PUBLISHED VERSION

https://doi.org/10.1016/j.optlaseng.2015.06.004

\section{PUBLISHER}

Elsevier BV

VERSION

AM (Accepted Manuscript)

\section{PUBLISHER STATEMENT}

This paper was accepted for publication in the journal Optics and Lasers in Engineering and the definitive published version is available at https://doi.org/10.1016/j.optlaseng.2015.06.004.

LICENCE

CC BY-NC-ND 4.0

\section{REPOSITORY RECORD}

He, Baofeng, Jon Petzing, Patrick Webb, and Richard Leach. 2015. "Improving Copper Plating Adhesion on Glass Using Laser Machining Techniques and Areal Surface Texture Parameters”. Loughborough University. 


\title{
Improving copper plating adhesion on glass using laser machining techniques and areal surface texture parameters
}

\author{
Baofeng $\mathrm{He}^{1}$, Jon Petzing ${ }^{2}$, Patrick Webb ${ }^{2}$, Richard Leach ${ }^{3}$
}

1. Beijing Engineering Research Center of Precision Measurement Technology and Instruments, Beijing University of Technology, 100 Ping Le Yuan, Chaoyang District, Beijing 100124, China

2. Wolfson School of Mechanical and Manufacturing Engineering, Loughborough University, Loughborough, LE11 3TU, UK

3. The Faculty of Engineering, University of Nottingham, University Park, Nottingham, NG7 2RD, UK

\author{
Corresponding Author: Dr Baofeng He \\ Email: baofenghe@aliyun.com \\ Phone number: +008618610040321
}




\begin{abstract}
Glass is a promising substitute substrate material being evaluated for electronic packaging technology. Improving the electroless copper plated layer adhesion of the glass is one of the most important considerations for development of the technology. An excimer laser (248 nm) was used for structured texturing of glass surfaces (to improve adhesion) by changing mask dimensions, laser operating parameters and overlapping pitch spacing, and therefore producing a range of micro-scale features. Electroless plated copper adhesion strength was assessed using quantitative scratch testing, demonstrating that micro-patterned structures can significantly improve copper/glass adhesion. New ISO 25178 part 2 areal surface texture parameters were used to characterise the surface roughness of ablated glass surfaces, and correlated to the scratch testing results. Highly correlated parameters were identified that could be used as predictive surface design tools, directly linking surface topography to adhesion performance, without the need for destructive adhesion quantification via scratch testing.
\end{abstract}

Keywords: excimer laser, glass, micro-patterning, adhesion, areal parameters. 


\section{Introduction}

Glass is a promising substitute substrate material which is being developed for use in electronic packaging technology and high density interconnect applications [1]. However, metallisation on smooth glass surfaces is difficult due to the physical, chemical and mechanical mismatches between the metal coating and the glass substrate [2, 3]. Without adequate adhesion, metallised coatings tend to delaminate and not perform the task for which they are intended. Improving the plated layer adhesion is, therefore, one of the most important considerations for development of glass substrate technology, although previous work has mostly considered the development of the interface chemical layers to promote active surfaces for copper deposition, or physically channelling glass and back-filling with copper [4], rather than relying on discrete surface modification.

The fundamental principles relevant to an understanding of the influence that interfacial roughness may have on adhesion have been well developed and discussed [5, 6], with surface pretreatment being one of the decisive factors for achieving a high-quality adhesive joint [7]. Previous work has identified that micro-columnar array (MCA) structures, produced by laser surface modification, could enhance the adhesive bonding strength for metals, alloys and ceramics [8-10]. The idea that adhesion depends on the mechanical interlocking of the adhesive with surface roughness is frequently discussed in the literature and is believed on a wide scale. According to this idea, mechanical adhesion occurs by the penetration of adhesives into pores, cavities and other irregularities on the surface of the substrate [11]. Therefore, increasing the roughness and structure formation on the glass substrate surface is thought to be a key enabler to improving copper/glass coating adhesion performance.

Whilst a number of mechanical or chemical techniques can be used to etch or machine glass [12], excimer lasers can be more effectively used for machining micro-structures on glass because of their potentially high machining accuracy [13]. Excimer laser systems are capable 
of machining micro-structures with feature sizes typically of the order of $1 \mu \mathrm{m}$ to $100 \mu \mathrm{m}$ and are applicable for glass-based materials [14]. Compared to visible wavelength lasers, the short UV wavelength range and pulse time ( $20 \mathrm{~ns})$ of eximer lasers allows the beam to be focused to a smaller spot, to obtain higher intensities and to have a smaller heat-affected zone at the work piece [15] for the effective removal of material from a target area. Likewise, such laser attributes allow for high resolution and high absorption in machining, which are important in making micro-structures with glass-based materials.

Depending on the electron-lattice coupling characteristics of the target material, excimer lasers are used in micro-machining applications to remove material from substrates, through the ablation mechanism, by either photo-thermal or photochemical mechanisms, or by a combination of the two $[16,17]$. The photochemical mechanism is often referred to as a non-thermal process because the material removal is caused by direct chemical bond decomposition as energy is absorbed, whereas in the photo-thermal process, the absorption laser energy is converted to lattice vibrational energy (thermal) causing melting and vaporisation of the material [18].

Glass can be removed without generating a large amount of heat during ablation, which can damage or shatter the surrounding material as a function of initial micro-cracking. This issue is especially important for brittle materials, although post-machining annealing techniques can be used to mitigate micro-cracking. The ablation mechanism with different glasses depends strongly on the composition of the glass. For a krypton fluoride $(\mathrm{KrF})$ excimer laser, photons with a wavelength of $248 \mathrm{~nm}$ have an energy of approximately $5 \mathrm{eV}$, which is sufficient to break chemical bonds, causing a sudden pressure increase within the absorption region and ejecting material in an explosive manner into vapour and particles [19]. Since excimer laser pulse durations are short, the interaction with the material occurs very rapidly, and the opportunity for thermal damage to the surrounding material is minimised. Subsequent development of laser technology is focussing on establishing the benefits of using nanosecond, 
picosecond and femtosecond laser sources for materials modification, with work being reported on the patterning of glasses, semiconductors and dielectrics [13, 20].

Whilst much work has been published over the years concerning the development of excimer laser systems and associated materials modification studies, comparatively little work has been reported concerning the relationship between laser operation parameter settings and machined surface roughness, especially in the context of the new ISO 25178 Part 2 areal surface texture parameters that have been developed over recent years for three dimensional surface texture characterisation [21-23]. When measured and reported, the surface texture of ablated structures has normally been assessed in the form of 2D surface profiles and ISO 4287 profile parameters, such as $R a$ [24].

The research reported here considers how to improve the mechanical adhesion of electroless copper plating to a glass substrate, as a function of laser machining parameters, and the production of a variety of novel micro-patterns. The result is complimented by an analysis of the applicability of ISO 25178 Part 2 areal parameters in the context of using them to describe these machined surfaces, correlating them with traditional scratch testing results of adhesion quality, and using them as potential predictive design indicators for the quality of the plating adhesion between copper and glass. The measurement of ISO 25178 Part 2 areal parameters would then obviate the need for destructive quantitative testing. It should also be noted that the eventual aim of the longer-term research and development, is to be able to machine circuit tracks into glass, thus large area surface patterning or structuring is desirable. 


\section{Laser setup}

A KrF excimer laser (model EMG 203, Lambda Physik), operating at $248 \mathrm{~nm}$, was used for machining commercially available uncoated CMG specification glass. CMG was chosen as a substrate material due to its thermal expansion coefficient, a key requirement for prototype glass substrates in order to minimise differential thermal expansion and residual stress with respect to silicon-based components. CMG glass is a borosilicate-type glass with a nominal cerium dioxide content and highly absorbing of light with a wavelength shorter than approximate $320 \mathrm{~nm}$, providing a comparatively low ablation threshold and accurate ablation contours [13]. The glass sheets were supplied as square samples (lateral size $40 \mathrm{~mm} \times 40 \mathrm{~mm}$, thickness of $100 \mu \mathrm{m}$ and $500 \mu \mathrm{m}$ respectively).

The duration of each laser pulse was fixed at $20 \mathrm{~ns}$. The laser beam passed through a beam delivery system (consisting of several optical components for beam expansion, shaping, scanning and image projection) that folded the beam in the vertical and horizontal directions and then projected onto the mask plane where it was passed through different sized and shaped mask apertures (1:10 image reduction at the work piece), thus tailoring the shape and size of the beam at the work piece as shown in Figure 1 [15]. Note that the glass substrates were mounted on a computer numerically controlled (CNC) X-Y table using G-Code programming. The laser system parameters included: output fluence or energy density, shots per area, and repetition rate; these being varied and optimised according to the surface topography requirements of the samples. Different brass masks with square, circular and triangular apertures (typically $1 \mathrm{~mm}$ in side length) were placed at the mask plane to tailor the size and the shape of laser beam projected onto the work pieces. 


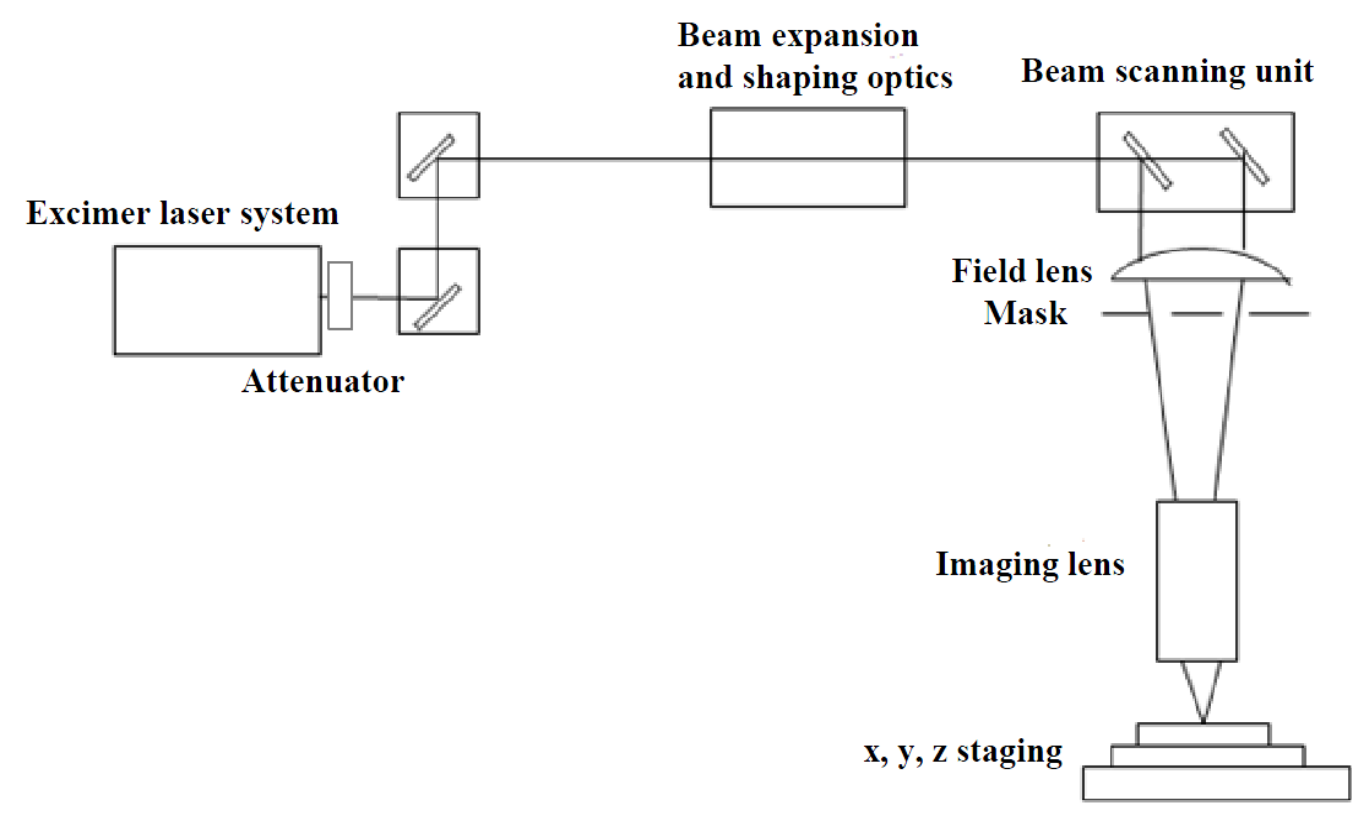

Fig.1 Schema showing the excimer laser setup 


\section{Laser operation parameters study}

Energy density, shots per area and pulse repetition rate are routinely used parameters in the literature $[25,26]$. These basic laser operation parameters were investigated systematically before the production of structured surfaces. This investigation was achieved by machining a matrix or grid of ablated features using a $1 \mathrm{~mm}$ circular mask, with one laser parameter being investigated per grid (e.g. energy density) - single position ablation producing vertical wells at each grid position. Mask dragging techniques were not employed at this stage.

\subsection{Laser fluence}

The energy density or the laser fluence, which is typically measured in $\left[\mathrm{J} \mathrm{cm}^{-2}\right]$, represents the energy input delivered into the work piece per unit surface area. This parameter is important for characterising the interaction process between the laser radiation and the work piece processing quality. Both the output pulse energy and attenuator position setting, which determine the energy density of the excimer laser, were pre-set by the CNC control system and, therefore, contributed to the etched depth and surface texture of the machined profiles.

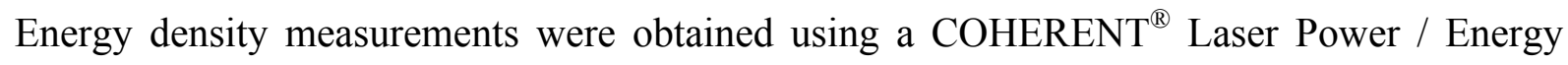
Meter.

A Zygo NewView 5000 coherence scanning interferometer (CSI) system (calibrated and traceable to the NIST defined metre standard) was used to measure the etch depth and areal surface topography of each machined circular feature or well [27]. Whilst a large number of areal parameters were available for selection, $S q$, the root mean square value of the ordinate values within a sampling area [23], was used to initially characterise the surface texture of each circular well because it indicates surface roughness in a well-known statistical form. The $S q$ parameter is given by

$$
S q=\sqrt{\frac{1}{A} \iint_{A} z^{2}(x, y) d x d y}
$$


where $A$ is the $x y$ area over which the parameter is calculated. $S q$ was generated and analysed using surface texture processing software (Digital Surf Mountains v5.1). It should be noted that the $S q$ parameter (as with all areal field parameters) is derived from the entire image set from the CSI measurement, rather than just a line profile typically used to generate the surface profile parameters. Consequently, $S q$ is a more statistically robust descriptor of the surface texture compared to its profile equivalent, $R q$.

Etch rate is a frequently-used term in laser machining literature. A mathematical relationship between the ablation depth and pulse number can be expressed as follows [19]:

$$
\Delta d=d / N
$$

where $d$ is the ablation depth, $N$ is the number of pulses or shots per area, and $\Delta d$ is the ablation depth per pulse (or the ablation rate) that can be determined experimentally.

In order to scale the relationship between ablation rate and energy density for CMG glass, energy densities of the machined dots in the matrix with varying output energy density were measured. Shots per area (25) and pulse repetition rate $(10 \mathrm{~Hz})$ were fixed for comparability. The results of energy density influence on etch rate are shown in Figures 2 and 3. 


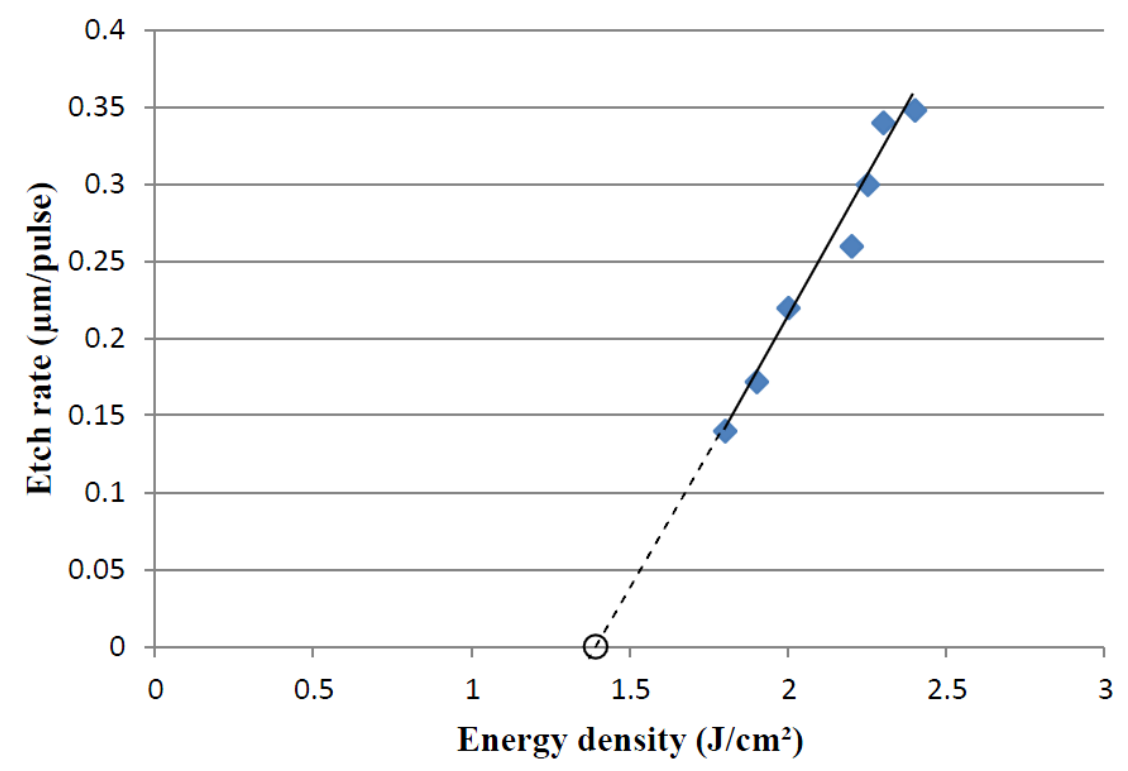

Fig.2 Relationship between energy density and etch rate

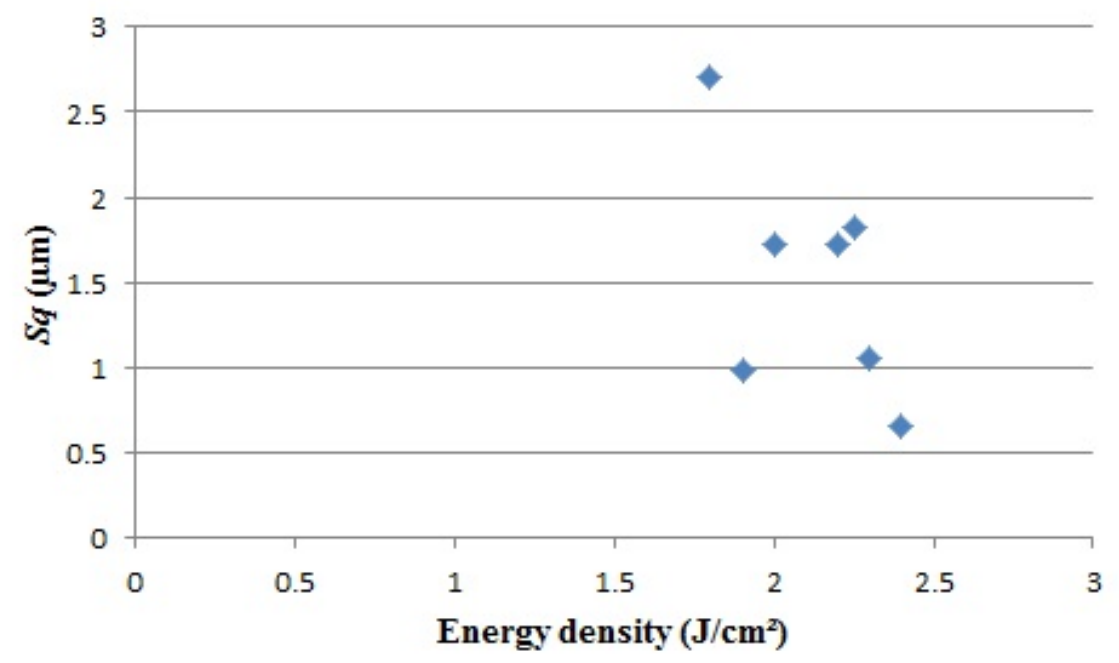

Fig.3 Relationship between energy density and $S q$

Figure 2 identifies that, as expected $[16,17]$, the etch rate increased almost linearly with the energy density, with the nominal minimum threshold to achieve glass removal being $1.4 \mathrm{~J} \mathrm{~cm}^{-2}$ (as shown by the circle on the abscissa in Figure 2). Figure 3 shows the relationship between energy density and measured $S q$ on the plateaux of the ablated wells, suggesting that higher energy density resulted in lower surface texture values. Figure 4 presents two typical microstructures of machined dots generated on the CMG glass surfaces. Visual analysis of the morphology of the ablated surfaces of the bottom of the machined circular wells showed 
smaller surface features, inconsistent sizing of surface features, and more surface smoothing, at the higher energy densities, again consistent with previously published results.

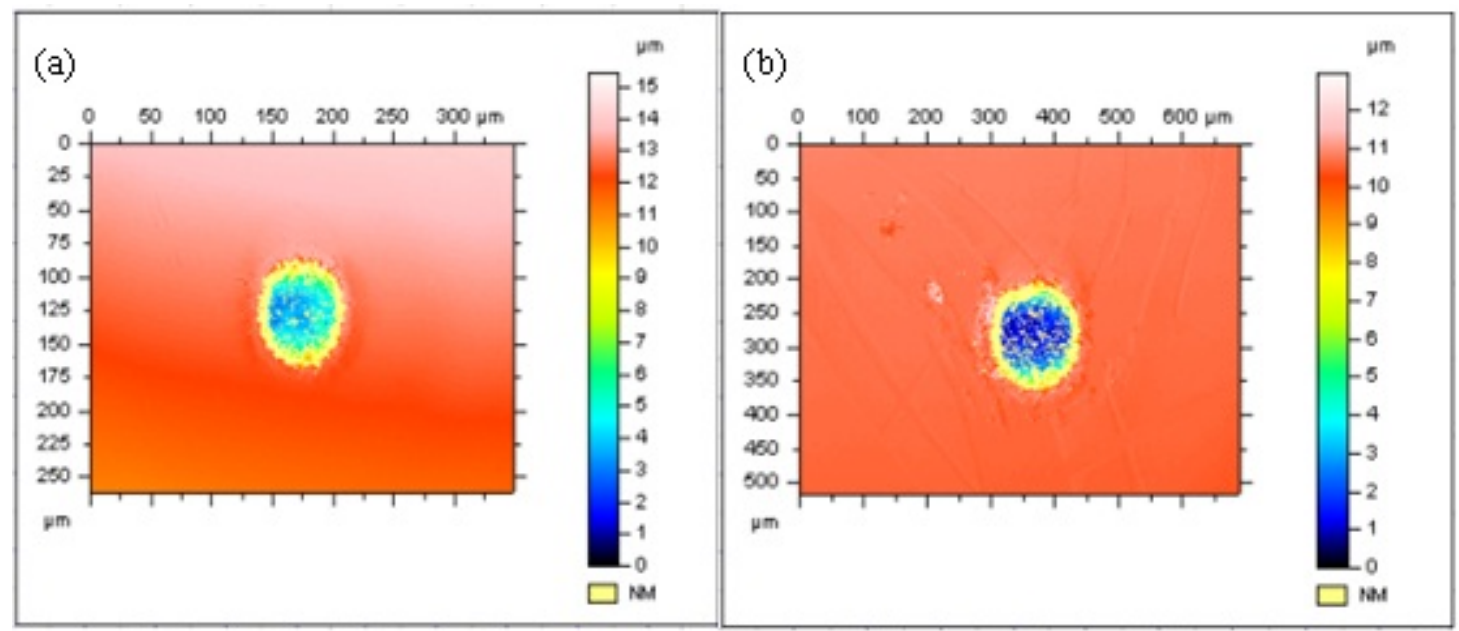

Fig.4 Machined dots with energy density (a) $2.3 \mathrm{~J} \mathrm{~cm}^{-2}$ (b) $2.5 \mathrm{~J} \mathrm{~cm}^{-2}$

Deviation in the $S q$ value away from a purely linear relationship could be a function of the pulsed, and typically inhomogeneous, nature of the energy density across the beam profile, with this unstable spatial output laser energy resulting in inhomogeneous machining of the surface topography [15]. The investigation indicated that the etch rate and the surface texture level can be controlled via energy density, which is determined by the laser output pulse energy and attenuator position.

\subsection{Shots per area}

The laser shots per area, $N$, was determined by the size of the mask, the laser repetition rate and the feed rate. The relationship can be expressed as

$$
N=60 L R / F
$$

where $L$ is the laser beam length in the direction of the beam's movement, $R$ is the laser pulse repetition rate and $F$ is the feed rate (speed of work stage movement). 
In order to study the effect of shots per area, further circular wells were machined (and measured) using a circular mask with varying shots per area, a fixed energy density of $2.2 \mathrm{~J} \mathrm{~cm}^{-2}$ and a repetition rate of $10 \mathrm{~Hz}$. The measurement results are shown in Figures 5 and 6.

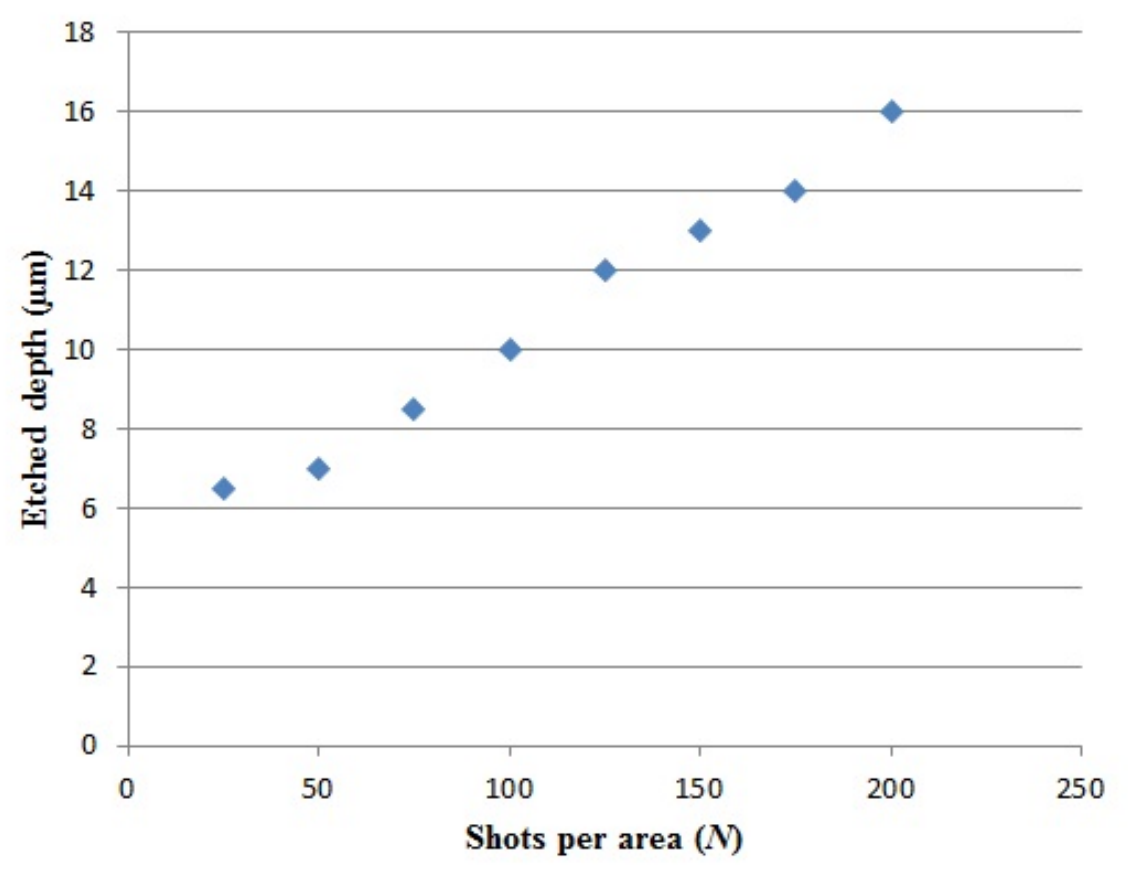

Fig.5 Relationship between shots per area and etched depth

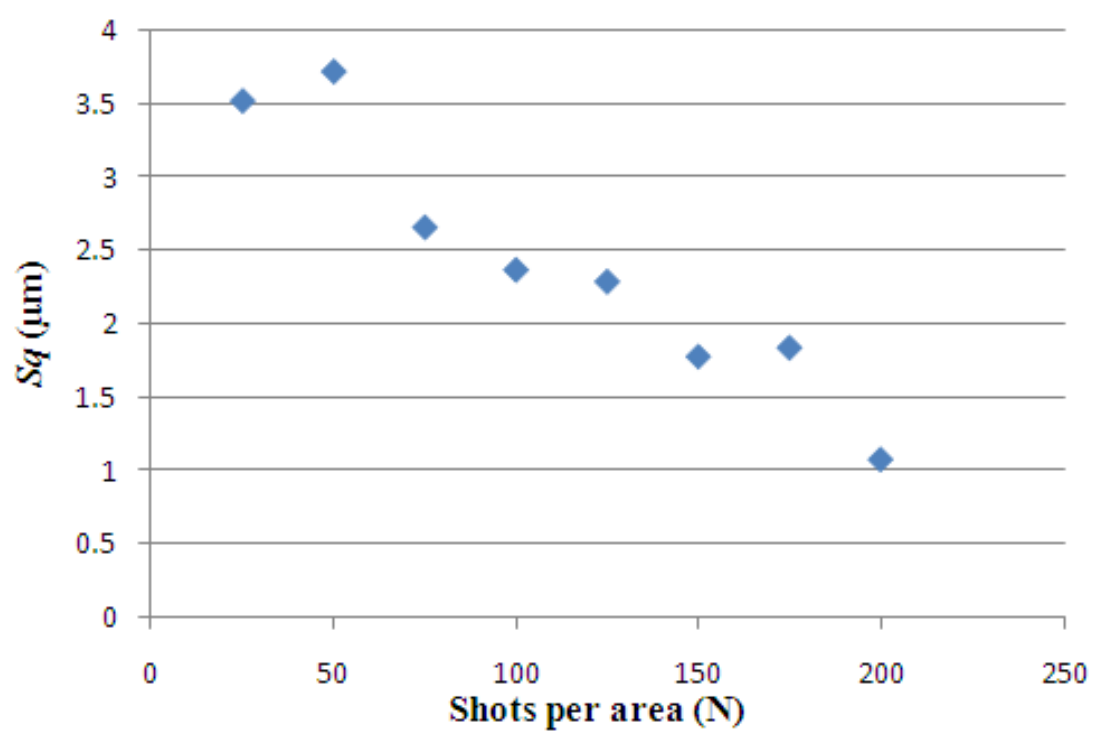

Fig.6 Relationship between shots per area and $S q$ 
Figure 5 shows the expected linear relationship between shots per area and the etched depth, consistent with previously published results $[16,17,28]$. When shots per area increased from 25 to 200 , the etched depths increased from $6.5 \mu \mathrm{m}$ to $16 \mu \mathrm{m}$ accordingly. Figure 6 shows the glass surface machining quality as a function of shots per area, again characterised using the $S q$ parameter. The near linear relationship shown with the $S q$ result suggests that the more shots per area (200), the more uniform the machined surface, reinforcing the analysis provided by Figure 3.

\subsection{Repetition rate}

In order to study the effect of repetition rate on the depths of laser structuring and subsequent surface texture, experiments were carried out in which the repetition rate was changed whilst other parameters were fixed (energy density $2.2 \mathrm{~J} \mathrm{~cm}^{-2}$, shots per area 25 ). The measurement results are shown in Figures 7 and 8.

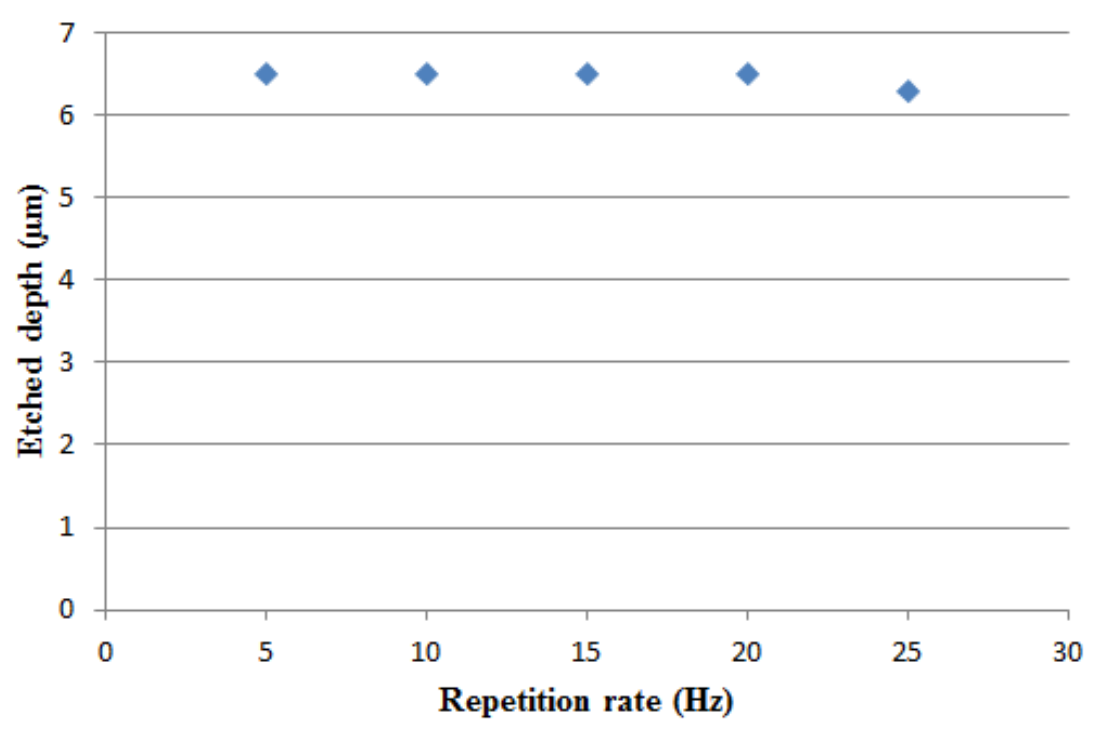

Fig.7 Relationship between repetition rate and etched depth 


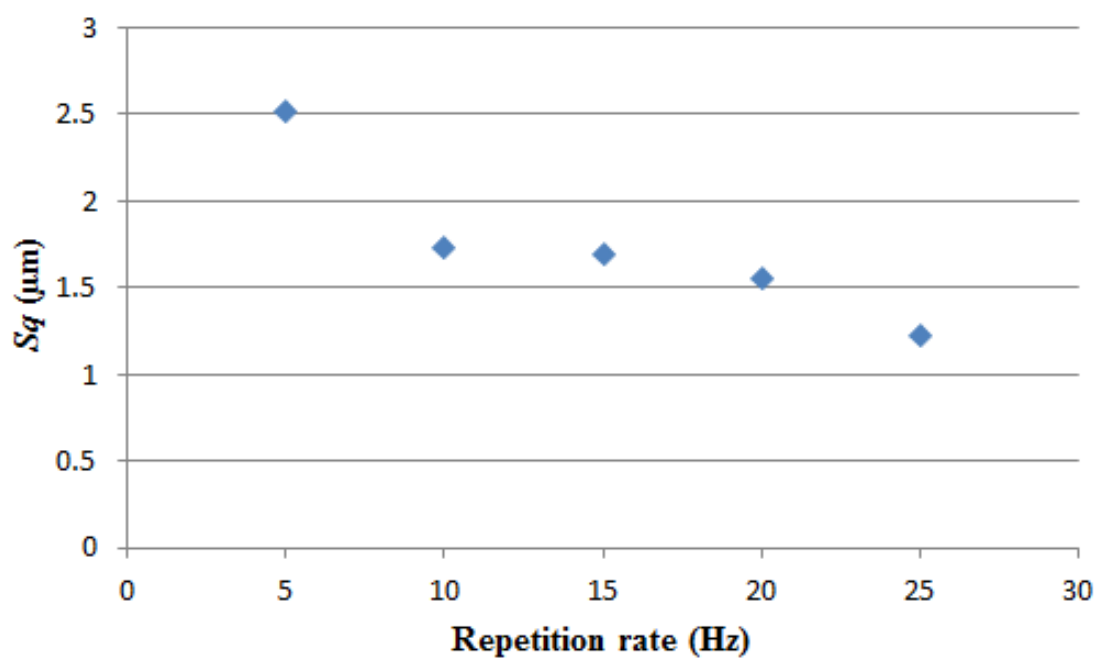

Fig.8 Relationship between repetition rate and $S q$

As anticipated, Figure 7 demonstrates that repetition rate has very little effect on the etched depth because (apart from random fluctuations in pulse to pulse energy) there is no change to the total energy delivered to the work piece surface with varying repetition rate. However, repetition rate determines machining speed - a higher repetition rate accelerates the machining process and improves the ablation efficiency, although potentially at the cost of process quality.

Figure 8 shows the relationship between repetition rate and machined surface texture, again characterised by the $S q$ parameter. The results indicate that lower pulse repetition rate leads to rougher machined surface quality, whilst higher pulse repetition rates result in smoother surfaces. This may be due to debris or recast from laser ablation having sufficient time to cool down and accumulate into larger debris at low pulse repetition rates, resulting in a rougher surface. Conversely, at high pulse repetition rates, the debris can be further ablated by the subsequent laser pulses and scattered into much finer components, resulting in smoother surface topography [17].

These preliminary results suggest the etched depth depends on laser energy density and shots per area, and machining homogeneity can be improved by increasing the energy density, shots per area and laser pulse repetition rate. More importantly, the work has identified the 
correlation and validity of using areal parameters (in this case the $S q$ parameter) to measure the quality of the random roughness of the machined surface. This is particularly relevant, because the $S q$ values can then potentially be used to correlate with the quality of copper adhesion when electroless plating is used, thus providing a direct relationship between potential mechanical adhesion performance of metallisation against laser machining process control. 


\section{Micro-feature pattern generating}

As previously identified, copper tracks on glass substrates require large area (millimetres square) preparation of the glass surface prior to electroless copper plating. Consequently, a mask projection and dragging process was used to generate micro-pattern array structures on CMG glass surfaces using techniques similar to those previously described [29-31]. In the work presented here, different shapes of mask aperture were used including circular, square and equilateral triangular, all independently fixed on a mask holder. Because the excimer laser beam was pulsed, and typically inhomogeneous across the beam profile, the masks were placed in the nominal centre of the laser beam to obtain the optimal laser output quality.

In two axis machining, complex micro-structure was produced using a two-step process. Firstly, the work piece was translated at constant velocity to form a groove contour along one direction, the length of the groove being user selectable (typically $5 \mathrm{~mm}$ to $10 \mathrm{~mm}$ ). A second groove was generated by overlapping the previous groove partially by a pitch length. Secondly, grooves were machined in a direction orthogonal to the initially-machined grooves. The same structure was machined after rotating the sample by $90^{\circ}$ to create a periodic structure. The mask dragging process is illustrated in Figure 9. 


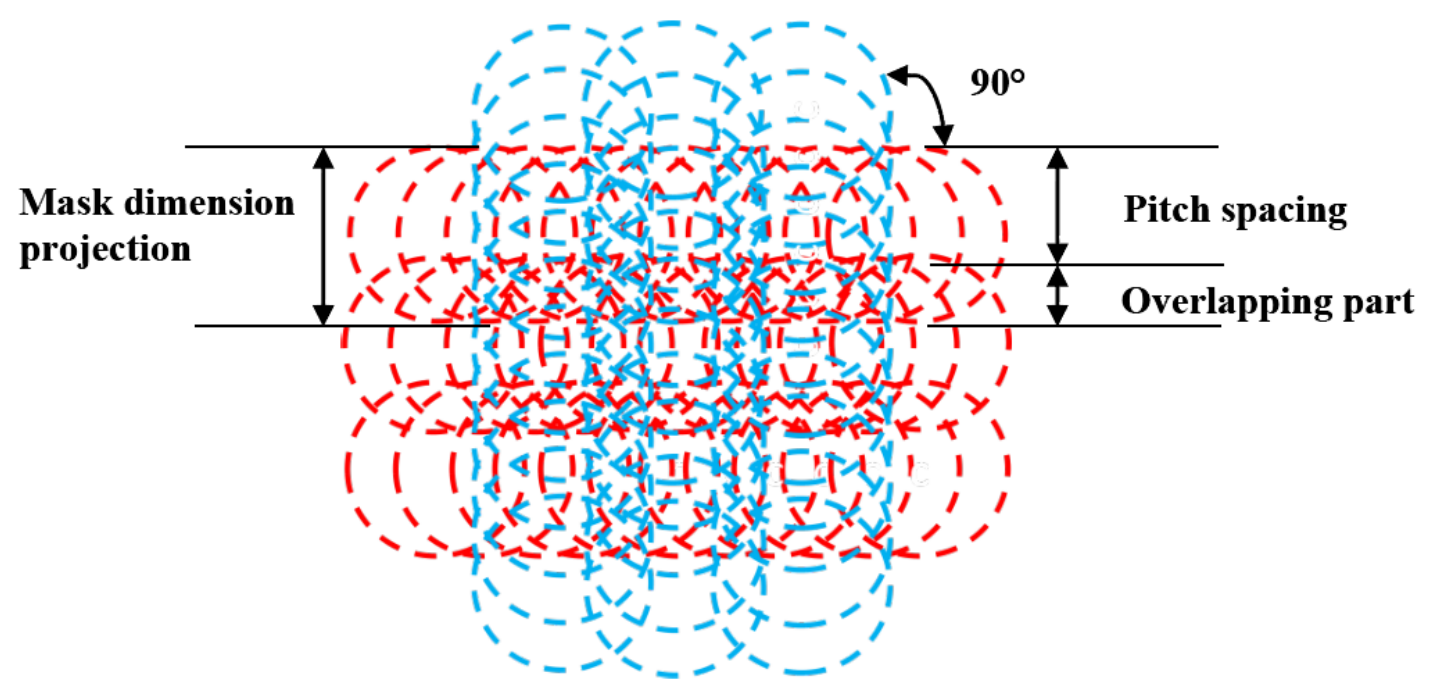

Fig.9 Mask dragging process using a circular mask

Micro-pattern structures were generated using circular masks and subsequently square masks. Surface topography images are shown in Figure 10 and detailed processing parameters of machined examples are shown in Table 1. The surface topography of the micro-pattern structures were measured using the CSI system and ISO 25178 Part 2 areal surface texture parameters were generated, as previously described. Figure 10 demonstrates that grid-based micro-structures can be generated on the CMG glass surfaces by using circular and square masks and these four micro-pattern structures exhibit different compositions, micro-roughness characteristics and etched depths, due to the different laser parameter settings. Compared to circular mask processing, there are three distinct levels of depth on the surface by applying square masks, and sharp edges instead of pits amid the micro-patterns. 
(a)

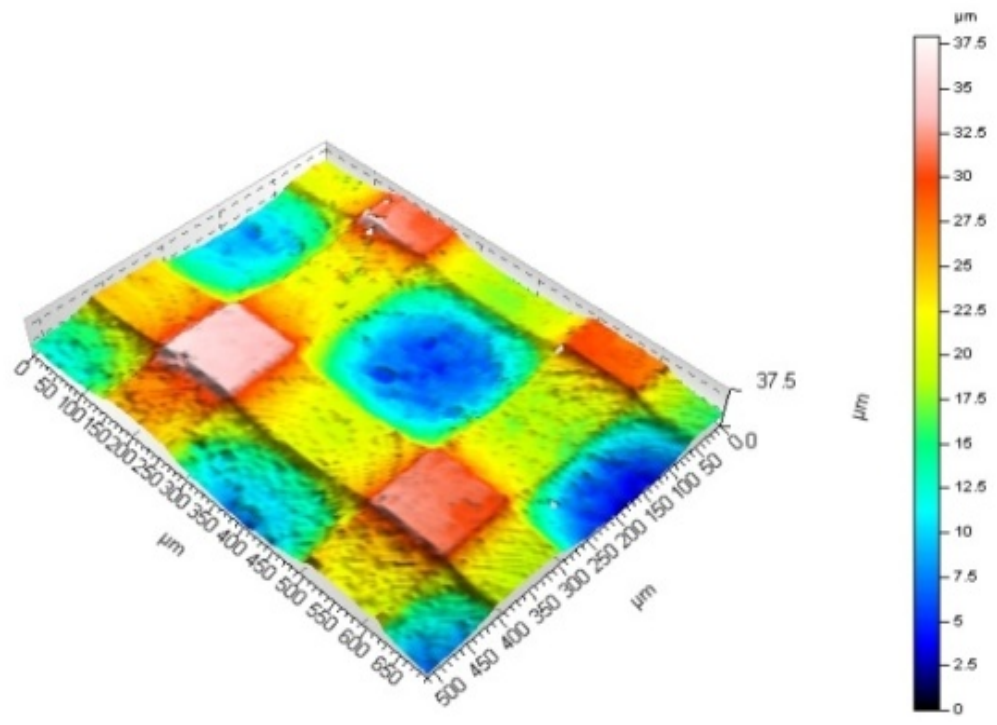

(b)

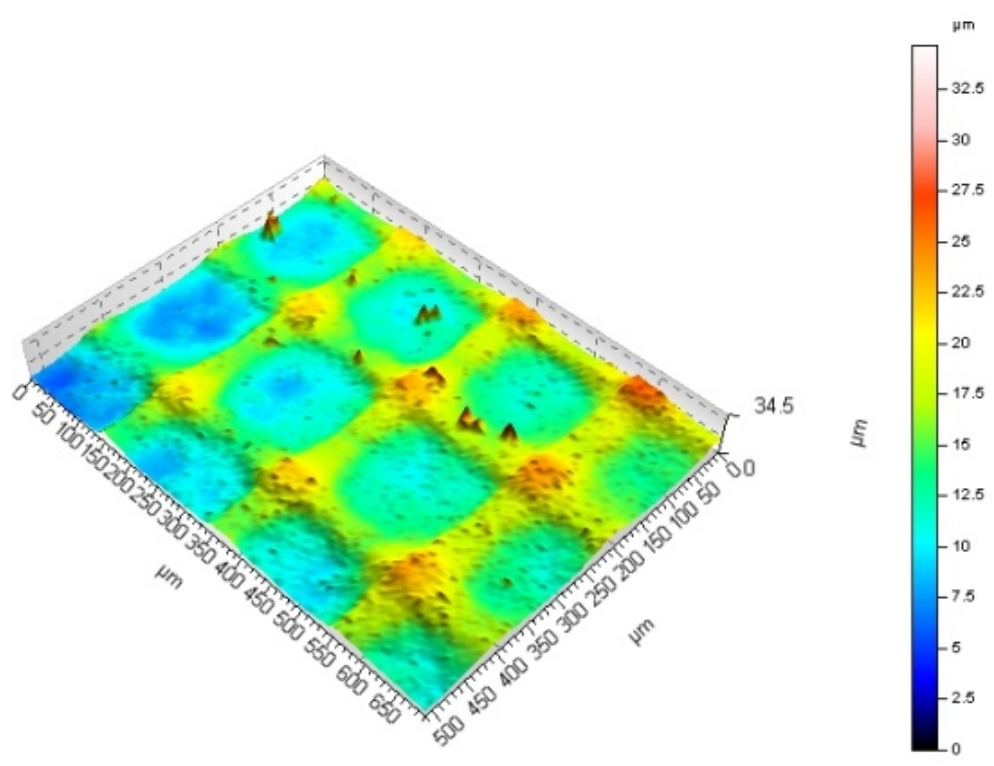


(c)

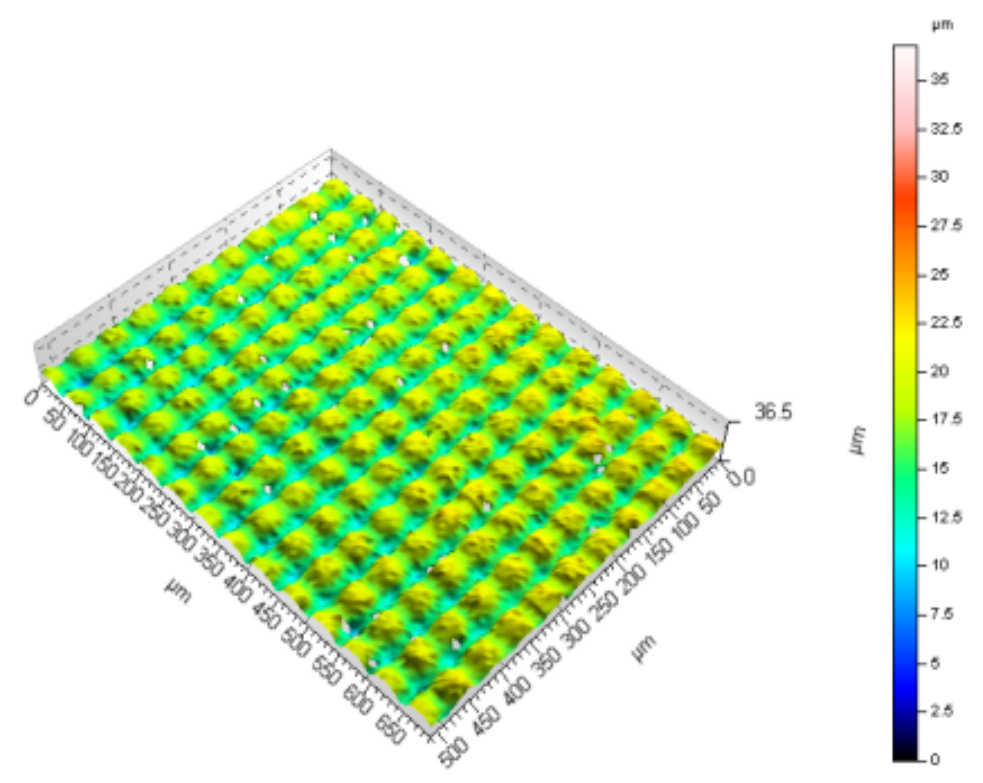

(d)
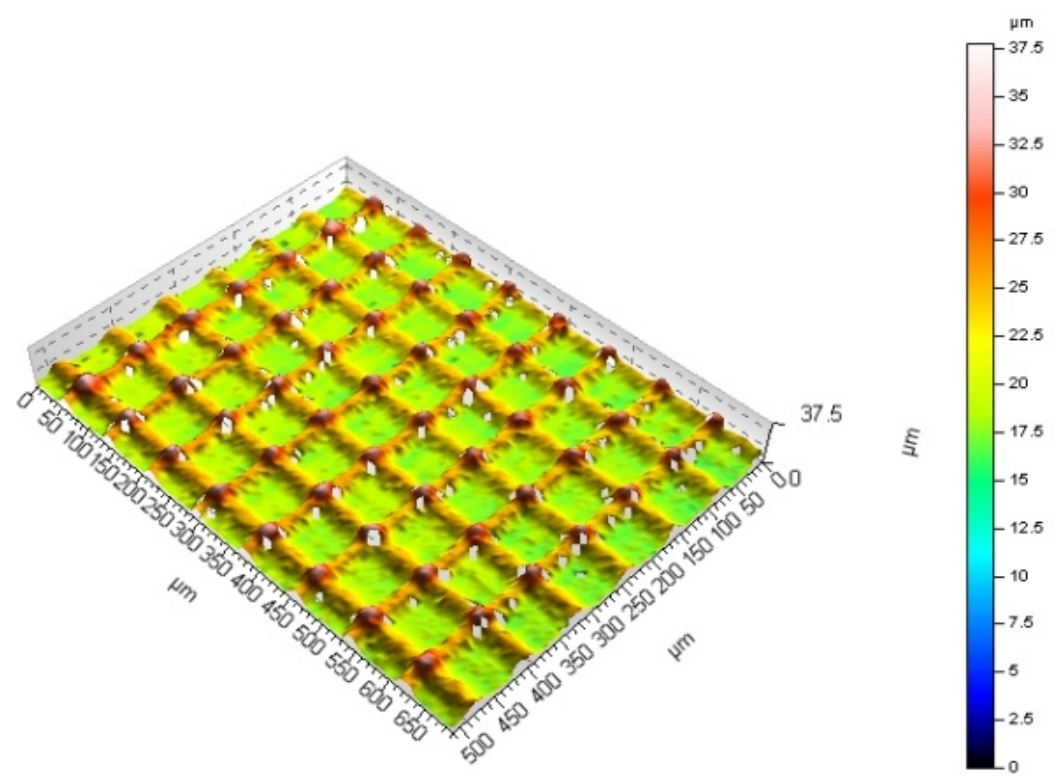

Fig. 10 (a-d) Micro-pattern structures 
Table 1 Processing parameters details for structures shown in Fig. 10

\begin{tabular}{ccccccc}
\hline Sample & $\begin{array}{c}\text { Mask } \\
\text { shape }\end{array}$ & $\begin{array}{c}\text { Mask } \\
\text { diameter } \\
/ \mathrm{mm}\end{array}$ & $\begin{array}{c}\text { Energy } \\
\text { density } \\
/ \mathrm{J} \mathrm{cm}^{-2}\end{array}$ & $\begin{array}{c}\text { Repetition } \\
\text { rate } \\
/ \mathrm{Hz}\end{array}$ & $\begin{array}{c}\text { Shots } \\
\text { per area }\end{array}$ & $\begin{array}{c}\text { Feature } \\
\text { pitch } \\
\text { spacing } \\
/ \mu \mathrm{m}\end{array}$ \\
\hline (a) & Circular & 7 & 2.4 & 20 & 15 & 350 \\
(b) & Circular & 5 & 2.4 & 10 & 5 & 200 \\
(c) & Square & 1 & 2.2 & 10 & 10 & 50 \\
(d) & Square & 1 & 2.4 & 10 & 10 & 80 \\
\hline
\end{tabular}

It is noticed that the features of the micro pattern structures are determined by the mask geometrical dimensions and the pitch spacing between adjacent grooves. Large scale structure spacings $(250 \mu \mathrm{m}$ and $200 \mu \mathrm{m})$, as shown in Figure 10 (a) and (b), can be controlled by the large laser mask geometrical dimensions $(7 \mathrm{~mm}$ and $5 \mathrm{~mm})$ and pitch spacings $(350 \mu \mathrm{m}$ and $200 \mu \mathrm{m})$. On the contrary, small scale structure spacings $(20 \mu \mathrm{m}$ and $50 \mu \mathrm{m})$, as shown in Figure 10 (c) and (d), are determined by the small mask geometrical dimensions ( $1 \mathrm{~mm}$ and 1 $\mathrm{mm})$ and pitch spacings $(50 \mu \mathrm{m}$ and $80 \mu \mathrm{m})$. As discussed previously, the depth of the machined feature and micro-roughness component can be controlled by changing the excimer laser operation parameters; energy density and shots per area. Deep etched depths (30 $\mu \mathrm{m})$, as shown in Figure 10 (a), were generated by larger laser energy density $\left(2.4 \mathrm{~J} \mathrm{~cm}^{-2}\right)$ and more shots per area (15). In comparison, shallow etched depths (10 $\mu \mathrm{m}$ in (b), $7.5 \mu \mathrm{m}$ in (c) and 12 $\mu \mathrm{m}$ in (d)) were a function of smaller laser energy density $\left(2.2 \mathrm{~J} \mathrm{~cm}^{-2}\right)$ and shots per area (5 and 10).

Three different aspect ratios of triangular masks were used to produce micro-structured surfaces. Mask shapes and dimensions were used as shown in Figure 11. Surface topography images are shown in Figure 12 and detailed operating parameters are identified in Table 2. 
(a)

(b)

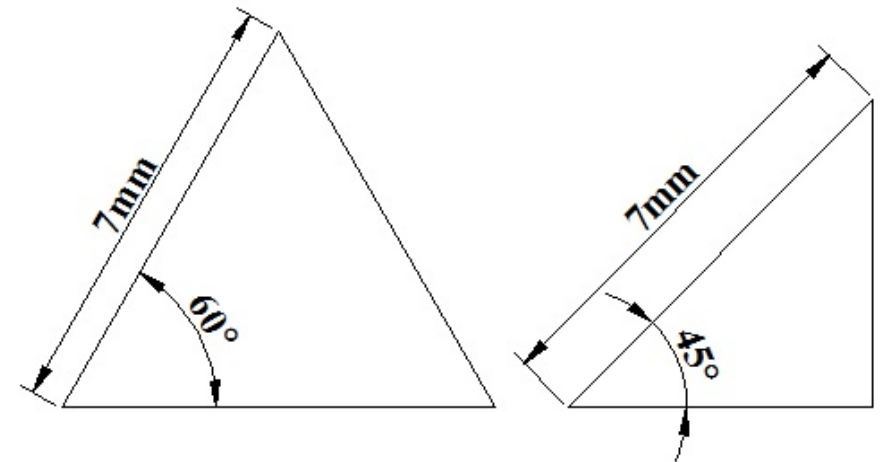

(c)

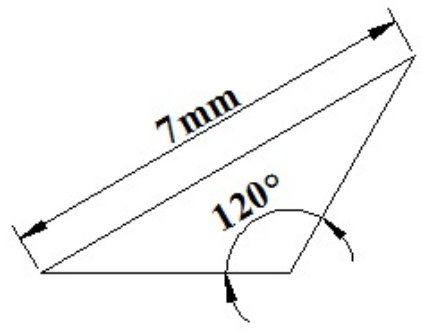

Fig. 11 (a-c) Schematic triangular masks

(a)

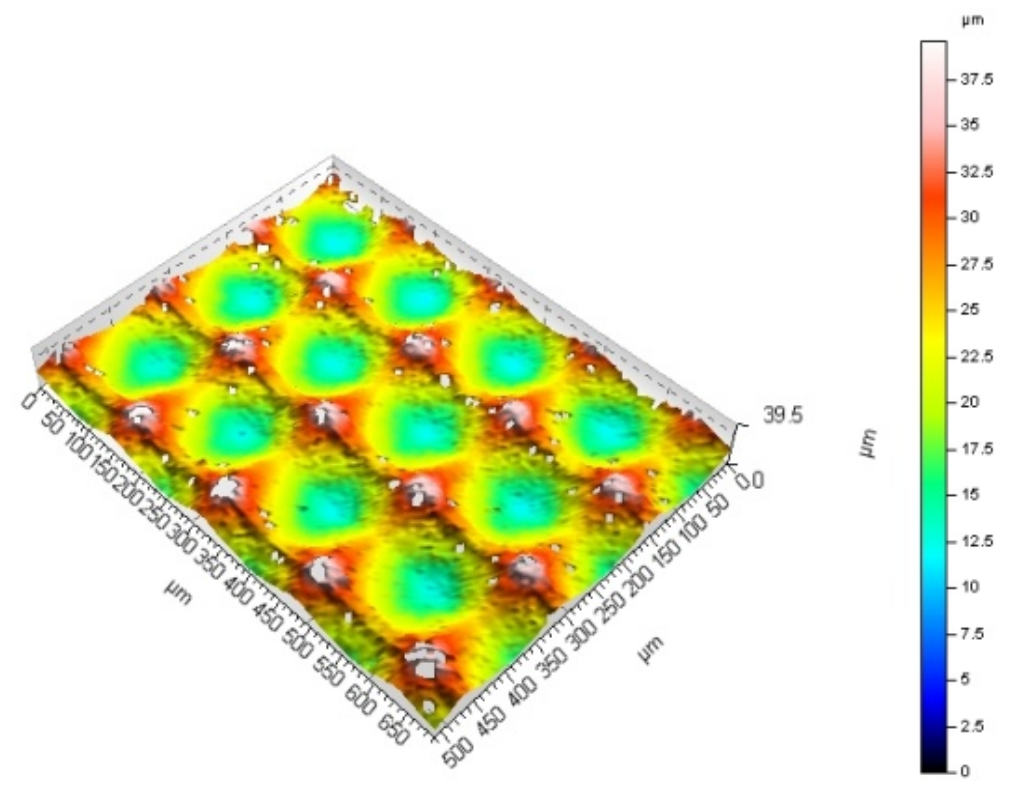


(b)

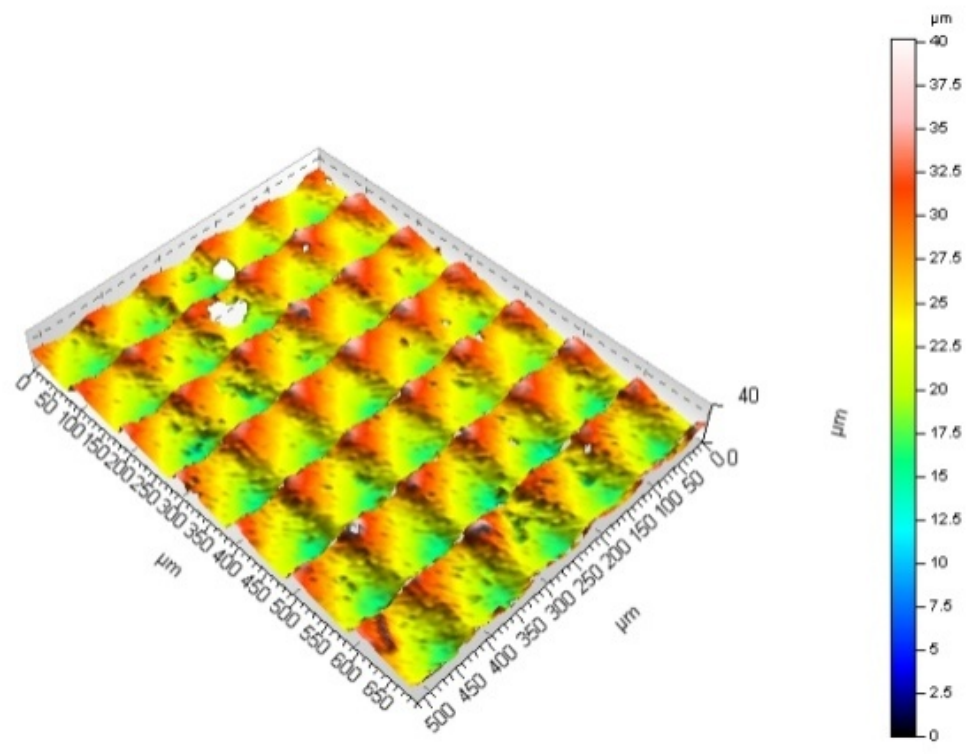

(c)

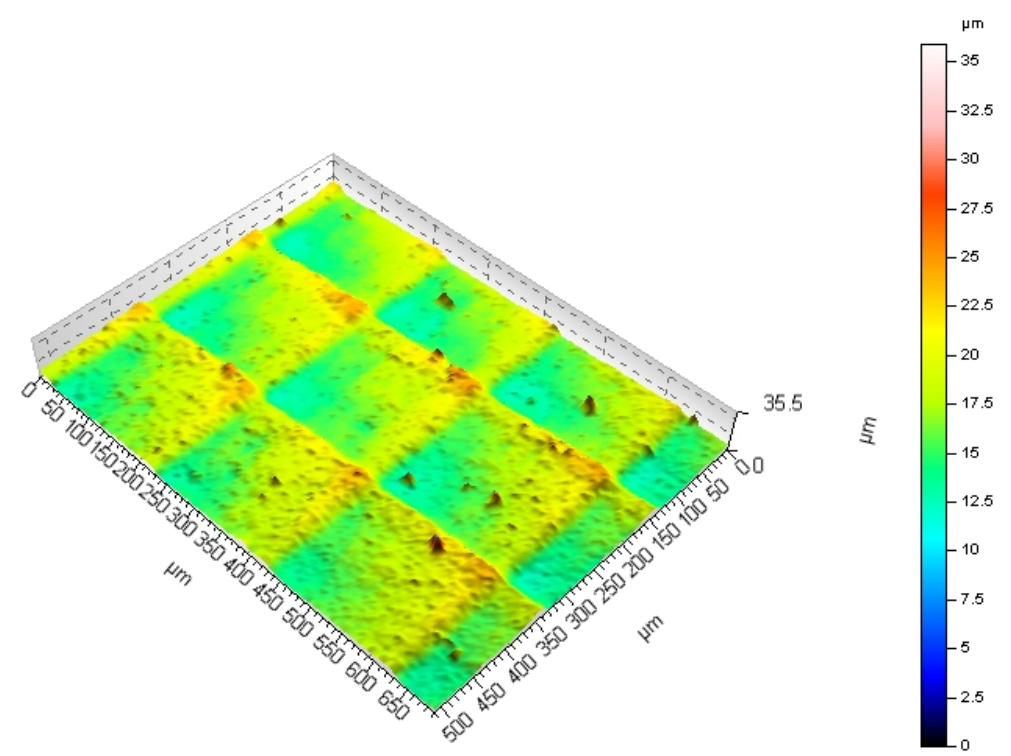


(d)

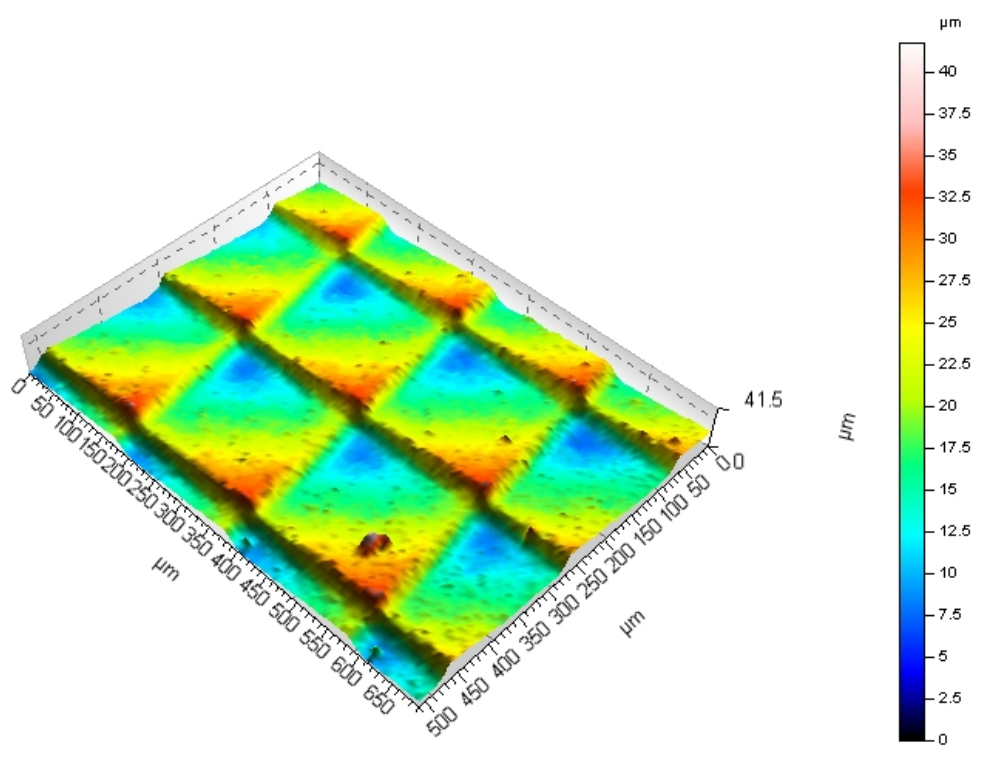

Fig. 12 (a-d) Micro-pattern structures machined using triangular masks

Table 2 Processing parameters details for structures shown in Fig. 12

\begin{tabular}{cccccc}
\hline $\begin{array}{c}\text { Sample } \\
\text { number }\end{array}$ & Mask shape & $\begin{array}{c}\text { Energy } \\
\text { density } / \\
\mathrm{J} \mathrm{cm}^{-2}\end{array}$ & $\begin{array}{c}\text { Repetition } \\
\text { rate } \\
/ \mathrm{Hz}\end{array}$ & $\begin{array}{c}\text { Shots per } \\
\text { area }\end{array}$ & $\begin{array}{c}\text { Feature } \\
\text { pitch } \\
\text { spacing } \\
/ \mu \mathrm{m}\end{array}$ \\
\hline (a) & Fig.11 (a) & 2.2 & 10 & 10 & 160 \\
(b) & Fig.11 (a) & 2.2 & 20 & 5 & 100 \\
(c) & Fig.11 (b) & 2.2 & 5 & 20 & 200 \\
(d) & Fig.11 (c) & 2.2 & 5 & 20 & 200 \\
\hline
\end{tabular}

Figure 12 presents typical micro-ramp and pyramid-based micro-structures created on the CMG glass surfaces using triangular masks, with micro-feature dimensions determined by mask shape, aspect ratio and geometrical dimensions, laser parameter settings and pitch spacing between adjacent grooves during the machining process. However, the micro-structure features machined by triangular masks are also related to the mask initial position. Figure 12 (a) exhibits micro-pyramid structures, but Figure 12 (b) exhibits micro-ramp structures. This is because the mask initial orientations on the mask holder were different, resulting in material ablation directions being different as illustrated in Figure 13. In these examples (Figure 12 (c) and (d)), pitch spacings were both set to $200 \mu \mathrm{m}$. As a result, the micro-feature dimensions produced were both $200 \mu \mathrm{m} \times 200 \mu \mathrm{m}$. 
Besides the laser processing parameters, the etched depths are also related to the mask dimensions. However, the etched depth of the micro-ramp produced by the isosceles obtuse-angled triangular mask in Figure 12 (d), was $15 \mu \mathrm{m}$, which is much deeper than using the isosceles right-angled triangular mask in Figure 12 (c) $(10 \mu \mathrm{m})$. The micro-roughness can be controlled by the laser operation parameter settings, such as energy density, shots per area and repetition rate. Note also that the fine structure (shown in Figure 12 (b)) can be produced by applying a $100 \mu \mathrm{m}$ pitch spacing.

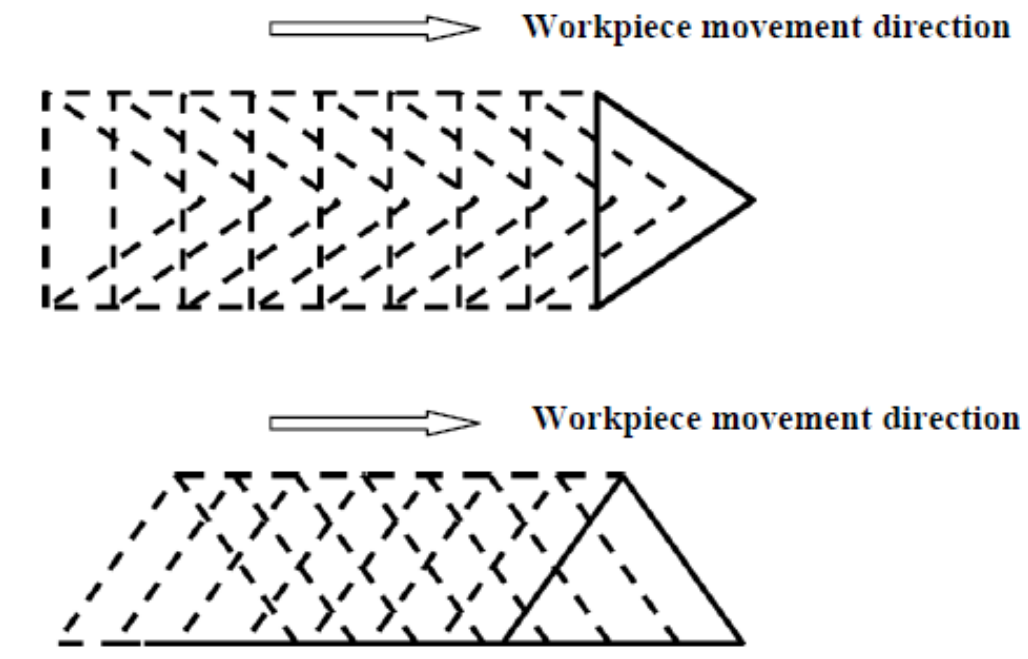

Fig. 13 Micro-structure characteristics determined by mask orientation 


\section{Scratch testing on plated glass}

Copper adhesion quality is traditionally tested using quantitative scratch testing techniques, which provide an identification of the critical load of failure for different plated substrates. Unfortunately, scratch testing, as its name implies, is a destructive testing procedure. In scratch testing, a diamond stylus is drawn across the coated surface with a constant or increasing load (stepwise or linear) against the sample, until failure occurs. Coating failure is traditionally defined as the point where surface defects are visually identified, at a load that is often termed the critical load, $L c$ [32].

Scratches were visualised after testing using an OGP FLASH 200 optical coordinate measuring machine (calibrated and traceable to the UKAS defined metre standard). This technique allowed visual differentiation between cohesive failure within the coating and adhesive failure at the interface of the coating/substrate system. Failure points along the scratch were typically distinguished by backlighting penetrating through the copper layer.

In this study, the scratch testing was undertaken using a Teer ST3001 instrument based at the UK National Physical Laboratory, employing ramp loading from $1.0 \mathrm{~N}$ to $15.0 \mathrm{~N}$ with 30 steps, at a loading rate of $15.0 \mathrm{~N}$ per minute and scratch lengths of $5 \mathrm{~mm}$. Figure 14 illustrates scratch testing results on an electroless copper coating deposited on the CMG glass surface before (Figure 14 (a)) and after excimer laser machining (Figure 14 (b)). The sample shown in Figure 14 (b) was machined using a square mask (side length $4 \mathrm{~mm}$ ), energy density of 2.2 $\mathrm{J} \mathrm{cm}^{-2}, 10$ shots per area and a repetition rate of $20 \mathrm{~Hz}$, resulting in surface patterning similar to that shown in Figure 10 (c). 


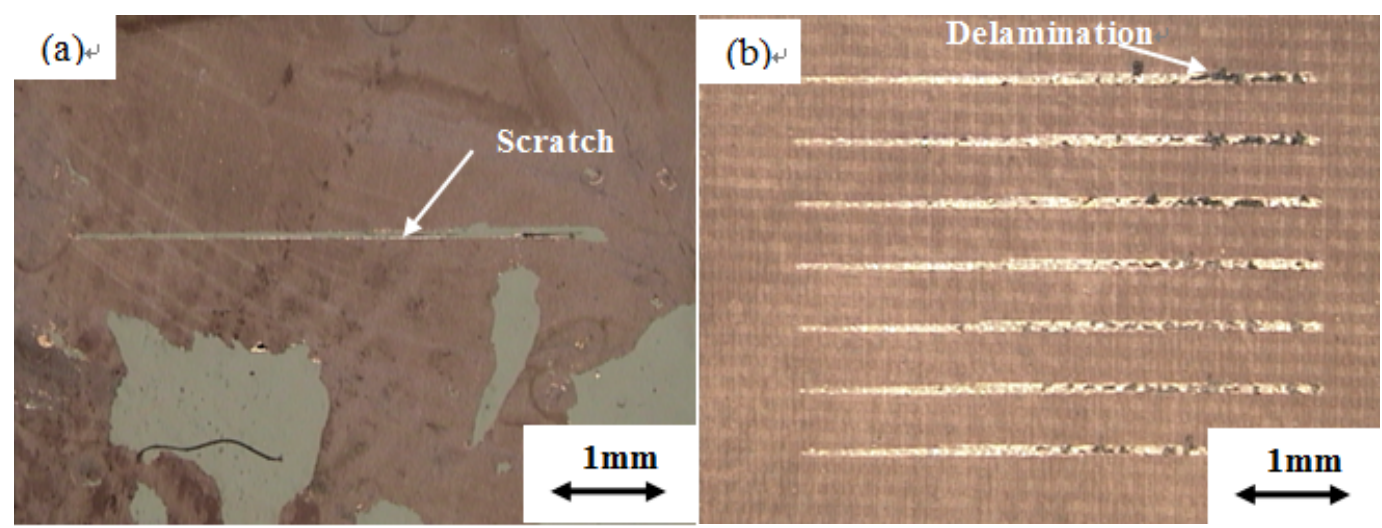

Fig. 14 Scratch testing tracks on CMG glass (a) smooth surface (b) laser machined surface

The critical load was defined as the loading start point when the coating delamination occurred. The results in Figure 14 (a) identified that coating penetration and delamination failure occurred almost immediately on smooth glass, indicating that the critical load for a copper coating was less than $1.0 \mathrm{~N}$, and signified very poor adhesion. However, the excimer laser-processed CMG glass surface shown in Figure 14 (b) significantly improved the adhesion between the electroless copper coating and the glass substrate. The onset of coating penetration and delamination failure occurred close to the end of the $5 \mathrm{~mm}$ tracks, with critical load recorded as $12.6 \mathrm{~N}$ in this example.

Scratch testing results demonstrated that structured surfaces (depending on pattern type) improve the mechanical adhesive bonding of electroless copper plating. This is a function of the micro-pattern array structures increasing surface contact area between the glass substrate and the copper, and in addition, further micro-roughness on the flanks of the patterned features may also potentially help to mechanically trap copper plating on the glass surface.

However, whilst single spot machining surface topography (detailed in Section 3) could be quantified using the $S q$ parameter, the regularly structured nature of the large area patterning presents two challenges when considering surface topography measurement. Firstly, the periodic structures are large scale (e.g. $10 \mu \mathrm{m}$ to $200 \mu \mathrm{m}$ depending on mask and parameters), but secondly, the micro-roughness apparent on the flanks and surfaces of each patterned 
element (as can be seen in Figures 10 and 12) is small scale (e.g. $1 \mu \mathrm{m}$ to $5 \mu \mathrm{m}$ ). Consequently, a broader range of areal parameters were investigated for applicability to quantify the surfaces.

ISO 25178 Part 2 currently details forty different types of $S$ and $V$ areal parameters [21,23]. Prior analysis of the derivations of each parameter reduced this down to nineteen relevant parameters that could potentially quantify characteristics of the laser machined surfaces, in one way or another. Machined glass surfaces were measured with the CSI system and a range of areal parameters generated using the DigitalSurf software. All parameter values were then individually plotted and correlated against relevant scratch testing critical load values, with Pearson and Spearman correlation coefficients being calculated. Table 3 identifies the leading areal parameters, in terms of quality of correlation. In the context of this research and the fact that the CMG glass surfaces were machined using the square masks, recommended numerical ranges were identified for each parameter which should indicate a surface suitable for high mechanical bond strength electroless copper plating.

Table 3 Rank ordered areal parameters

\begin{tabular}{cccc}
\hline $\begin{array}{c}\text { Areal } \\
\text { parameters }\end{array}$ & $\begin{array}{c}\text { Spearman Coefficient } \\
\text { Value }(r)\end{array}$ & $\begin{array}{c}\text { Pearson } \\
\text { Coefficient } \\
\text { value }(\rho)\end{array}$ & Recommended value \\
\hline$V m c$ & -0.74 & -0.77 & $0.4 \mu \mathrm{m}^{3} / \mu \mathrm{m}^{2}-1.5 \mu \mathrm{m}^{3} / \mu \mathrm{m}^{2}$ \\
$V v$ & -0.72 & -0.74 & $0.5 \mu \mathrm{m}^{3} / \mu \mathrm{m}^{2}-2 \mu \mathrm{m}^{3} / \mu \mathrm{m}^{2}$ \\
$S q$ & -0.71 & -0.74 & $1 \mu \mathrm{m}-2.5 \mu \mathrm{m}$ \\
$V v c$ & -0.70 & -0.73 & $0.5 \mu \mathrm{m}^{3} / \mu \mathrm{m}^{2}-1.5 \mu \mathrm{m}^{3} / \mathrm{m}^{2}$ \\
$S d q$ & -0.66 & -0.69 & $0.5-1$ \\
$S x p$ & -0.63 & -0.61 & $0.5 \mu \mathrm{m}-5 \mu \mathrm{m}$ \\
$S d r$ & -0.61 & -0.64 & $10 \%-50 \%$ \\
\hline
\end{tabular}




\section{Conclusions}

This work demonstrates the feasibility of using an excimer laser machining system to generate a variety of micro-structured surface textures on CMG glass by changing mask dimensions, laser operating parameters (energy density, shots per area and repetition rate), and mask overlapping patterns. The ablation or etch depth depends on the laser fluence and shots per area, and machining homogeneity can be improved by increasing the energy density, shots per area and laser pulse repetition rate. These conclusions help to use this technique to maximise the use of the laser energy and minimise the machining time, and the controllability of the laser surface treatment can be optimised via the processing parameters.

The surface topography consists of both the large-scale grid structure elements and smaller-scale micro-roughness components. The large-scale structure is determined by mask geometry, pitch spacing between the adjacent grooves and mask initial start orientation. The micro-roughness component is affected by laser operation parameters, such as energy density, shots per area and repetition rate.

Scratch testing of electroless copper plated samples has demonstrated significant improvements in mechanical copper adhesion to the CMG glass, as a function of micro-machined patterning. Moreover, application of ISO 25178 Part 2 areal parameters has identified a subset of $S$ and $V$ parameters that correlate well with the respective scratch testing results. Consequently, it is now possible to laser machine CMG glass surfaces and determine their suitability for electroless copper plating as a function of the measurement of their actual surface texture, rather than having to rely on destructive scratch testing after electroless copper plating. This means that areal parameters can potentially be considered as predictive design tools for laser machined surfaces before other plating or manufacturing operations are carried out on the relevant substrate.

It should be noted that post machining annealing of the glass samples was not employed, because any micro-cracking that occurred as a function of laser processing was not considered 
important in the context of this specific research. Clearly, further development of the techniques described in this report would most probably employ post-process heat treatment, and further measurement of surface topography may, therefore, be required to reinforce the validity of the observed correlations. Furthermore, electroless plating of copper would act as a precursor to electroplating of copper on the predefined copper tracks, in order to increase copper thickness and current carrying capability. It is anticipated that further testing and evaluation would be required to assess the integrity and functionality of any final copper track build in this instance. 


\section{Acknowledgements}

This research was completed as a collaboration between Loughborough University (UK) and the UK National Physical Laboratory. The research was part funded by the UK EPSRC (Engineering and Physical Sciences Research Council) 3D-Mintegration Grand Challenge project (EP/C534212/1), the Wolfson School of Mechanical \& Manufacturing Engineering, and the 2008 to 2011 UK NMO (National Measurement Office) Engineering \& Flow Metrology Programme. The authors would also like to thank Qioptiq Ltd for the supply of CMG glass. 


\section{References}

[1] Lau, JH and Lee RSW. Microvias: low cost, high density interconnects. London: McGraw-Hill; 2000.

[2] Su W, Yao L, Yang F, Li P, Chen J and Liang L. Electroless plating of copper on surface-modified glass substrate. App Surface Sci 2011; 257: 8067-8071.

[3] Cui X, Hutt DA and Conway P. Evolution of microstructure and electrical conductivity of electroless copper deposits on a glass substrate. Thin Solid Films 2012; 520: 6095-6099.

[4] Hutt DA, Williams K, Conway PP, Khoshnaw FM, Cui X and Bhatt D. Challenges in the manufacture of glass substrates for electrical and optical interconnect. Circuit World 2007;33(1):22-30.

[5] Packham D E. Surface energy, surface topography and adhesion. Int J Adhes Adhes $2003 ; 23: 437-48$.

[6] Da Silva LFM, Öchsner A and Adams RD. Handbook of Adhesion Technology (Vol. 1). Heidelberg: Springer; 2011.

[7] Balden A. Review: adhesively bonded joints and repairs in metallic alloy, polymers and composite materials: adhesives, adhesion theories and surface pretreatment. J Mater Sci 2004;39:1-49.

[8] Starikov D, Boney C, Pillai R, Bensaoula A, Shafeev GA, Simakin AV. Spectral and surface analysis of heated micro-column arrays fabricated by laser-assisted surface modification. Infrared Phys Techn 2004;45:159-67.

[9] Baburaj EG, Starikov D, Evans J, Shafeev GA, Bensaoula A. Enhancement of adhesive joint strength by laser surface modification. Int J Adhes Adhes 2007;27:268-76.

[10]Zhang XM, Yue TM, Man HC. Enhancement of ceramic-to-metal adhesive bonding by excimer laser surface treatment. Mater Lett 1997;30:327-32.

[11]Ebnesaijad S. Adhesive technology handbook. 2nd ed. New York: William Andrew Inc; 2008.

[12]Hülsenberg D, Harnisch A, Bismarck A. Microstructuring of Glasses. Heidelberg: Springer; 2008. 
[13]Bekesi J, Meinertz J, Simon P, Ihlemann J. Sub-500-nm patterning of glass by nanosecond KrF excimer laser. Appl Phys A 2013;110:17-21.

[14]Chen YT, Ma K J, Zhou JG, Tseng AA. Excimer laser ablation of glass-based arrayed microstructures for biomedical, mechanical and optical applications. J Laser Appl $2005 ; 17: 38-46$.

[15]Crafer RC, Oakley PJ. Laser Processing in Manufacturing. London: Chapman and Hall; 1993.

[16]Tseng AA, Chen Y, Chao C, Ma K, Chen TP. Recent developments on microablation of glass materials using excimer lasers. Opt Laser Eng 2007;45:975-92.

[17]Chen YT, Ma KJ, Tseng AA, Chen PH. Projection ablation of glass-based single and arrayed microstructures. Opt Laser Technol 2005;37:271-80.

[18]Harvey EC, Rumsby PT, Gower MC, Remnant JL. Microstructuring by Excimer Laser. Micromachining and Microfabrication Process Technology, SPIE, 1995; 2639:266-77.

[19]Tseng AA. Recent developments in micromachining of fused silica and quartz using excimer lasers. Phys Status Solidi A 2007;204:709-29.

[20]Bonse J, Krüger J, Höhm S, Rosenfeld A. Femtosecond laser-induced periodic surface structures. J. Laser Apps 2012;24:042006-1 to 042006-7.

[21]Leach R. Characterisation of areal surface texture. Heidelberg: Springer; 2013.

[22]He B, Petzing J, Conway P, Webb P, Leach R, NPL Report Eng 34. London: HMSO; 2012.

[23]ISO 25178-2, Geometrical product specifications (GPS) - Surface texture: Areal - Part 2: Terms, definitions and surface texture parameters. Geneva: ISO; 2010.

[24]ISO 4287, Geometrical product specification (GPS) - Surface texture: Profile Method: Terms, definitions and surface texture parameters. Geneva: ISO; 2000.

[25]Delmdahl R, and Pätzel R. Excimer laser technology trends. J. Phys. D: Appl. Phys. 2014;47:1-7.

[26]Tseng AA, Chen YT, Ma KJ. Fabrication of high-aspect-ratio microstructures using excimer laser. Opt Lasers Eng 2004;41:827-47. 
[27]Petzing JN, Coupland JM, Leach R. NPL Measurement GPG No.116 - The Measurement of Rough Surface Topography using Coherence Scanning Interferometry. London: HMSO; 2010.

[28]Kautek W, Kruger J, Lenzer M, Sartania S, Spielmann C, Krausz F. Laser ablation of dielectrics with pulse durations between 20 fs and 3 ps. Appl Phys Lett 1996;69:3146-8.

[29] Wang SY. A computer simulation for mask-shape effect in the fabrication of an aspheric micro lens array by using a dragging process with excimer laser. J Micromech Microeng 2005;15:1310-16.

[30]Harvey EC and Rumsby PT. Fabrication techniques and their application to produce novel micromachined structures and devices using excimer laser mask projection, Micromachining and Microfabrication Process Technology III, SPIE, 1997;3223:26.

[31]Rizvi NH. Production of novel 3D microstructures using excimer laser mask projection techniques, Design. Test and Microfabrication of MEMS and MOEMS, SPIE, 1999;3680:546-52.

[32]Bull SJ, Berasetegui EG. An overview of the potential of quantitative coating adhesion measurement by scratch testing. Tribol Int 2006;39:99-114. 